\title{
OLDER PEOPLE FACING THE CRISIS OF COVID-19: BETWEEN FRAGILITY AND RESILIENCE
}

\author{
H. AMIEVA, J.-A. AVILA-FUNES, S. CAILLOT-RANJEVA, J.-F. DARTIGUES, M. KOLECK, \\ L. LETENNEUR, M. PECH, K. PÉRÈS, N. RAOUX, N. RASCLE, C. OUVRARD, M. TABUE-TEGUO, \\ R. VILLENEUVE, V. BERGUA
}

INSERM, Bordeaux Population Health Research Center, UMR 1219, Univ. Bordeaux, F-33000 Bordeaux, France Corresponding author: Professor Helene Amieva, Inserm U 1219 Bordeaux Population Health, University of Bordeaux, 146 Rue Léo Saignant, 33076 Bordeaux cedex, France, Phone: +33557571510/Fax: +335575714 86, Helene.Amieva@u-bordeaux.fr

\begin{abstract}
The health crisis we are facing is challenging seniors' resources and capacities for adaptation and resilience. The PACOVID survey, set up a few days after containment, investigates their psychological and social experiences with regard to the COVID-19 crisis and to what extent these characteristics, representations and attitudes have an impact on health and mortality. A telephone survey is being carried out on 935 people already followed up in the framework of ongoing epidemiological studies. As we are writing this article, the interviews conducted during the containment have just ended. Even though we will have to wait for the analysis of the results to draw conclusions, words collected by the psychologists during the interviews already illustrate a great heterogeneity in the way older adults lived this experience: social isolation, anxiety, the importance of family and the difficulty of being deprived of it, but also remarkable coping skills and resilience capacities.
\end{abstract}

Key words: Containment, behaviors, vulnerability, coping, resilience.

J Frailty Aging 2021;10(2)184-186

Published online November 18, 2020, http:/ / dx.doi.org/10.14283/jfa.2020.60

In the face of health crises, the older population is one of the most vulnerable. The heat wave episode in France in August 2003 exceptional in terms of intensity, duration and geographical extent, clearly demonstrated this. The excess mortality related to this episode $(15,000$ additional deaths compared to the usual mortality) was explained by an increase in excess mortality with age particularly marked among people living alone at home or in nursing homes (1). While the world is still facing the COVID-19 epidemic, there is every reason to believe that older people will once again be the most affected, as shown by the mortality curves provided by the countries affected by the pandemic. This excess mortality can be explained by the physiological particularities of the older persons (a greater state of immuno-depression, a propensity to over-activate the inflammatory response, and the frequent co-morbidities such as heart failure or chronic obstructive bronchopneumopathy, favoring complications), but the specificities related to the psychological and social functioning of the older adults also contribute to this issue. Apart from any crisis situation, the consequences of a disease are very different from one older person to another depending on psychological resources, lifestyle, level of social support, home facilities, accessibility of services and shops, etc. Numerous studies have shown that socially isolated older adults present higher mortality, independently of many confounding factors (2-4). Depression also has a major impact on mortality of the older persons suffering from diseases such as cancer (5), as depressed people adhere less to preventive screening procedures, good health behaviors, and treatments. In a major health crisis, do these factors carry more weight? As few studies explored in Received June 2, 2020

Accepted for publication June 10, 2020 depth this question, it is difficult to answer this question.

In the days following the containment measures in China, a literature review was undertaken to take stock of what is known about the psychological impact of quarantine (6). Based on 24 studies, the conclusions highlight the psychological impact, the most frequent consequences being post-traumatic stress symptoms, confusion and anger. These symptoms persist for several months or even years after quarantine. For example, in Wu et al.'s study (7) conducted during the SARS epidemic, quarantine predicted post-traumatic stress up to 3 years later Brooks et al. (6) also highlight the factors that contribute to the negative impact: duration of quarantine, level of fear of infection, feelings of frustration, boredom, supply problems, lack of information, loss of income, and stigmatization.

No study specifically focused on the older population particularly at risk at least at three levels: with regard to the response to the infectious agent itself because of the physiological characteristics of this population; with regard to the psycho-social characteristics of the older persons which make part of this population even more exposed to the risk of severe repercussions of the infection (elders with dependency, cognitive disorders, depression, social isolation or living in institutions); and possibly with regard to the situation of containment due to reduced adjustment capacities $(8,9)$.

The PACOVID (Personnes Agées face au COVID19) survey was set up in Bordeaux region a few days after containment. Through a 2 -step telephone survey carried out during and after the confinement on 935 people (living at home or in institutions) already followed up in the framework of ongoing epidemiological studies, this project addresses the 


\section{THE JOURNAL OF FRAILTY \& AGING}

following questions:

1) What are the attitudes, psychological and social experiences of the older persons with regard to the COVID19 crisis and the containment measures: level of stress, coping strategies, social support, access to information, instructions and measures put in place by government authorities, understanding and compliance to such measures, representations of the epidemic, access to digital communication tools?

2) To what extent do these characteristics, representations and attitudes have an impact on mortality and health events related and unrelated to COVID-19?

As we are writing this article, the first wave of the survey conducted during the period of containment has just ended (the second wave will take place away from the containment). Even though we will have to wait for the analysis of the results to draw conclusions, words collected by the psychologists during the interviews already illustrate a great heterogeneity in the way older adults live this experience. First of all, this survey reminds us to what extent loneliness and social isolation are worrying issues among the older persons, such as this 98-yearold woman, pleasantly surprised by our telephone call and who told us that she had not seen anyone since Christmas, «I lost my husband at the beginning of the year, I've been in conflict with my only son for many years, I don't have any friends left, your call is very touching to me». For those who have more people around them, the importance of family and the difficulty of being deprived of it come out from numerous comments: «Usually, my children and grandchildren visit me at lunchtime, but now I feel alone and I miss them, we lose our appetite with my husband,» said one participant. Actually, several people told us that they apply the containment measures very strictly, even though it turned out during the interview that they continued to receive regular visits from their family, «Containment is for outsiders, the family is not the same. My children come to see me every day to bring me groceries, watch TV, help me with household chores. By the way, today my daughterin-law is coming to mow the lawn!» says one participant. As we expected, anxiety was very present, as in this 103-year-old woman who told us: «I suffer from rheumatism to the legs, my physiotherapist doesn't come anymore, I would have to walk but nobody can accompany me, I can't do anything!». This other 98-year-old participant even tells us: «You know, I pray every day, maybe I won't wake up tomorrow». Although frequent, these examples do not cover the whole range of experiences. Older people are not only vulnerable, they also have remarkable coping skills and resilience. A striking fact is that many people spontaneously referred to the parallel between this crisis and the war. «We old people know what it's like, we've been through war! It's the young people we worry about; they're not used to it». Another participant said: «When I see the long queues in front of the shops, the difficulty in finding certain foods, I feel like I am back in wartime! But you know, we know what it's like, we'll survive!». Another man makes the connection with his past as a soldier: "You know, this epidemic reminds me of the time when I was in the trenches, there was a huge epidemic, I fell through the cracks, I hope I will do it again this time!». For some, this containment is lived in the greatest serenity, like this older man, passionate about flowers, a former nurseryman who spends his days in his garden where he grows more than 50 varieties of rare flowers to the admiration of his neighbours. "COVID-19 has no impact on me, I've been confined to my garden since I retired, and I'm very happy that way!». In the same vein, this woman says: «I have my chickens, my garden, cleaning, knitting, I don't have time to be bored!». Another interesting testimony is that of a 97-year-old man who has settled for the confinement at his niece's house: «I live the best of my life, I enjoy it, I am taken care of, I eat delicious meals, I hope the containment will keep going for a while yet!» As may be seen here, lifestyle, selfesteem and the meaning one gives to one's life are determining factors in the way one experiences this confinement. In addition to the use of the telephone to keep in touch with beloved ones, digital tools equipped with simultaneous vision seem to have been new allies for some seniors during containment. For example, an older lady who was hosted in her daughter's home tolds us: «I have a great-granddaughter who was just born, my daughter hooked us up to the camera, you know with the phone, if you had seen how she looked at me, I'm so happy to be able to see her». Other participants told us that they wished they had known how to use these tools like this centenary lady: «You know if my children showed me how it works, I would have liked to use these tools, I'm not against these things, it would have helped me.»

The crisis we are facing is challenging seniors' resources and capacities for adaptation and resilience. While for some, maintaining balance seems easy, for others, containment will have serious consequences for psychological, cognitive and physical health. Isolation, anxiety and the absence of certain home care professionals may have increased certain risk situations such as frailty, falls, cognitive decline or lack of care. Thanks to the follow-up of participants enrolled in prospective cohorts, the results gathered from PACOVID will help characterizing the most vulnerable people, which is important to anticipate in the future medico-social actions to be implemented rapidly to support them.

Conflict of Interest: The authors declare they have no conflict of interest.

Funding: The PACOVID study is supported by the National Agency Research « Agence Nationale de la Recherche » [ANR-20COVI-0010-01]. The sponsor had no role in the design and conduct of the study; in the collection, analysis, and interpretation of data; in the preparation of the manuscript; or in the review or approval of the manuscript.

Ethical standards: This study is in accordance with the international ethical standards of research and with the 1964 Helsinki Declaration. 


\section{OLDER PEOPLE FACING THE CRISIS OF COVID-19}

\section{References}

1. Hémon D, Jougla E. Surmortalité liée à la canicule d'août 2003 : suivi de la mortalité (21 août - 31 décembre 2003), causes médicales des décès (1 - 20 août 2003). 2004;77.

2. Rubin R. Loneliness Might Be a Killer, but What's the Best Way to Protect Against It? JAMA. 2017; 318(19):1853-5.

3. Tabue Teguo M, Simo-Tabue N, Stoykova R, Meillon C, Cogne M, Amieva H, et al. Feelings of Loneliness and Living Alone as Predictors of Mortality in the Elderly: The PAQUID Study. Psychosom Med. 2016;78(8):904-9.

4. Tanskanen J, Anttila T. A Prospective Study of Social Isolation, Loneliness, and Mortality in Finland. Am J Public Health. 2016;106(11):2042-8.

5. Pinquart M, Duberstein PR. Depression and cancer mortality: a meta-analysis. Psychol Med. 2010;40(11):1797-810.
6. Brooks SK, Webster RK, Smith LE, Woodland L, Wessely S, Greenberg N, et al. The psychological impact of quarantine and how to reduce it: rapid review of the evidence. The Lancet. 2020;395(10227):912-20.

7. Wu P, Fang Y, Guan Z, Fan B, Kong J, Yao Z, et al. The psychological impact of the SARS epidemic on hospital employees in China: exposure, risk perception, and altruistic acceptance of risk. Can J Psychiatry Rev Can Psychiatr. 2009;54(5):302-11.

8. Charles ST. Strength and vulnerability integration: a model of emotional well-being across adulthood. Psychol Bull. 2010;136(6):1068-91.

9. Rothermund K, Brandstädter J. Coping With Deficits and Losses in Later Life: From Compensatory Action to Accommodation. Psychol Aging. 2003;18(4):896-905. 